\title{
Cultivo hidropônico de tomate cereja utilizando-se efluente tratado de uma indústria de sorvete
}

\author{
Samuel M. M. Malheiros ${ }^{1}$, Ênio F. de F. e Silva ${ }^{1}$, Pedro R. F. de Medeiros ${ }^{1}$, \\ Elvira M. R. Pedrosa ${ }^{1}$, Mario M. Rolim ${ }^{1} \&$ Alexandre N. Santos ${ }^{1}$
}

\begin{abstract}
RESU M O
O objetivo deste trabalho foi avaliar o uso de doses de efluente oriundo de indústria de sorvete, na cultura do tomate cereja em relação ao consumo hídrico e no desenvolvimento vegetativo em sistema hidropônico. 0 delineamento experimental foi o inteiramente casualizado, com seis tratamentos e quatro repetições. Os tratamentos foram compostos pelo uso de doses de efluente $(0,25,50,75$ e $100 \%$ ) com complementação de nutrientes e com o uso de $100 \%$ de efluente sem complementação nutriente. $O$ aumento das doses de efluente na solução nutritiva proporcionou redução linear no consumo hídrico. 0 efluente com $25 \%$ proporcionou a melhor produtividade. A adição de até $50 \%$ de efluente de sorvete à solução nutritiva permitiu o cultivo de tomate cereja sem redução na produtividade, com melhor eficiência do uso da água na produção de matéria seca da parte aérea, produção de frutos e máxima substituição de minerais solúveis na solução nutritiva.
\end{abstract}

Palavras-chave: Lycopersicon esculentum, reúso de água, solução nutritiva, consumo hídrico, biometria

\section{Hydroponic production of cherry tomatoes using treated effluent of ice cream industry}

\begin{abstract}
A B STRACT
The objective of this study was to evaluate the effect of ice cream raw effluent doses on consumption and vegetative development of cherry tomato under hydroponic system. The experiment was conducted in completely randomized design with six treatments and four replications. Treatments consisted of 5 different levels of effluent $(0,25,50,75$ and $100 \%)$ complemented with the amount of nutrient recommended for growing tomatoes and $100 \%$ of effluent without nutrient complementation. Increasing doses of effluent provided linear reduction in water consumption.Addition of effluent in proportion of $25 \%$ provided best production results. Addition up to $50 \%$ ice cream effluent to nutrient solution allowed grow th of cherry tomato without yield reduction providing better efficiency of water use in terms of dry weight of shoots and fruit production as well as maximum substitution of soluble mineral fertilizers in nutrient solution.
\end{abstract}

Key words: Lycopersicon esculentum, water reuse, nutrient solution, water consumption, biometry 


\section{INTRODUÇÃO}

No Brasil, o cultivo de tomate tem alto valor comercial, com uma área plantada de 60.292 ha e produção anual de 3,7 milhões de toneladas (Agrianual, 2009). Em termos de produção e consumo ocupa a segunda posição dentre as hortaliças, sendo que a maior parte da colheita se destina ao consumo in natura e o restante à agroindústria (Filgueira, 2008).

Devido à possibilidade do fruto do tomate ser consumido in natura, o produtor deve ter maior preocupação quanto à sanidade dos frutos, principalmente quando se utiliza água de baixa qualidade. O sistema hidropônico, do tipo NFT (fluxo laminar de nutrientes) demonstra ser ideal para a produção de hortaliças com a utilização de águas de baixa qualidade, ou seja, na oportunidade de reúso de água proveniente de esgoto industrial configurando, assim, mais uma vantagem dentre as diversas atribuídas a esse tipo de sistema de cultivo (Steidle Neto \& Zolnier, 2010).

Em alguns municípios brasileiros, sobretudo naqueles localizados em regiões com menor disponibilidade hídrica, a utilização de efluentes industriais na agricultura pode ser uma alternativa viável visando minimizar os problemas da escassez hídrica, além de ser fonte de nutrientes e de matéria orgânica, possibilitando o uso em diversas culturas agrícolas, aumento de produtividade e diminuição do impacto ambiental, uma vez que os lançamentos de efluentes nos corpos hídricos podem ser minimizados (Souza et al., 2010).

O quantitativo de nutrientes existentes nos efluentes pode variar em função da origem e da época (Bastos \& Mara, 1995). Os efluentes provenientes de indústria de sorvete geram águas residuárias com características salinas em virtude da utilização de salmoura no processo produtivo do sorvete, resultando em altos teores de íons, como sódio e cloreto, além da existência de altos teores de cálcio, originários do leite.

A salinidade nos efluentes é quantificada pela existência de íons solúveis, sendo atribuída principalmente à existência de sódio e cloreto porém a presença de outros cátions e ânions contribui para aumentar a salinidade (Paganini, 2003). Dependendo do quantitativo de íons na solução, a salinidade ocasiona diminuição do consumo hídrico nas plantas (Gomes et al., 2011), inibição do crescimento (Freire et al., 2010) e alteração na absorção de nutrientes minerais (Navarro et al., 2003) .

Em cultivos comerciais de tomate é muito comum a ocorrência de deficiência de cálcio associado à salinidade, ocasionando frutos com podridão apical ou "fundo preto" (Loos et al., 2008); necrose interna e morte da gema apical, originando perdas que podem atingir $50 \%$ da produtividade (Filgueira, 2008). Para minimizar o efeito da salinidade na inibição competitiva em plantas de tomate, a adição de cálcio na solução nutritiva tem diminuído o efeito maléfico do sódio (Tuna et al., 2007); logo, o uso de efluentes tratados provenientes de indústria de sorvete poderá minimizar a ocorrência de sintomas de deficiências e diminuir os custos de produção.

Deste modo objetivou-se, com o presente trabalho, avaliar o consumo hídrico e a produtividade do tomate cereja cultivado em sistema hidropônico submetido a doses crescentes de efluente tratado, proveniente de indústria de sorvete na formulação da solução nutritiva.

\section{MATERIAL E MÉTODOS}

O experimento foi conduzido no período de 22 de outubro de 2010 a 25 de fevereiro de 2011, em casa de vegetação localizada na área experimental do Departamento de Tecnologia Rural da Universidade Federal Rural de Pernambuco (UFRPE), Recife, PE, cujas coordenadas geográficas são $08^{\circ} 10^{\prime} 52^{\prime}$ de latitude Sul e $34^{\circ} 54^{\prime} 47^{\prime}$ de longitude Oeste e altitude de 5 m. O clima, de acordo com a classificação de Köppen, é do tipo As (tropical úmido), com precipitação e temperatura média anual de $1750 \mathrm{~mm}$ e $24^{\circ} \mathrm{C}$, respectivamente; o mês mais quente do ano possui registro máximo de temperatura de $29,9{ }^{\circ} \mathrm{C}$, representado pelo mês de fevereiro, enquanto a temperatura mínima de $19,2^{\circ} \mathrm{C}$ ocorre no mês de agosto.

A casa de vegetação utilizada tem $7 \mathrm{~m}$ de largura com $24 \mathrm{~m}$ de comprimento, $3 \mathrm{~m}$ de pé direito e $4,5 \mathrm{~m}$ de altura com cobertura em arco. As paredes laterais são constituídas de telas, com rodapé de $20 \mathrm{~cm}$ em alvenaria. A cobertura da casa de vegetação é feita com filme agrícola de polietileno transparente, com 150 $\mu \mathrm{m}$ de espessura e tratamento anti-ultravioleta. O piso é revestido com manta geotêxtil (bidim) de cor cinza.

Foram construídas 24 bancadas hidropônicas em sistema NFT (fluxo laminar de nutrientes), cada qual representava uma parcela experimental. As parcelas foram constituídas de um reservatório plástico com capacidade para $40 \mathrm{~L}$; uma eletrobomba de circulação do tipo centrifuga de rotor aberto $220 \mathrm{~V} 60 \mathrm{~Hz} 32 \mathrm{~W}$ com vazão máxima de $1800 \mathrm{~L} \mathrm{~h}^{-1}$; um perfil hidropônico feito em polipropileno com aditivo anti-ultravioleta com diâmetro de $0,15 \mathrm{~m}$ e 2,5 m de comprimento. O espaçamento adotado foi $0,90 \mathrm{~m}$ entre perfis e $0,50 \mathrm{~m}$ entre plantas, totalizando cinco plantas por perfil. Os perfis foram instalados a $0,50 \mathrm{~m}$ de altura da superfície de solo, com declividade de $3 \%$.

Foram utilizadas no experimento duas fontes de água: água do abastecimento (AA) proveniente do campus do Departamento de Tecnologia Rural da UFRPE e efluente industrial (EI) tratado com flotação e desinfecção com ácido paracético, oriundo de uma indústria de sorvetes localizada na Região Metropolitana de Recife, PE. A caracterização físicoquímica do efluente tratado (Tabela 1), nas distintas fases de desenvolvimento da cultura, faz-se necessário devido à variação, em referência ao quantitativo de nutrientes em virtude

Tabela 1. Características físicas e químicas da água de abastecimento e do efluente industrial, nas diferentes fases de cultivo

\begin{tabular}{lcccc}
\hline \multirow{2}{*}{ Parâmetro } & Água de & \multicolumn{3}{c}{ Efluente industrial } \\
\cline { 2 - 6 } abastecimento & Fase A & Fase B & Fase C \\
pH & 5,5 & 6,88 & 6,71 & 7,32 \\
$\mathrm{CE}\left(\mathrm{dS} \mathrm{m}{ }^{-1}\right)$ & 0,07 & 4,23 & 4,27 & 5,68 \\
Fósforo $\left(\mathrm{mg} \mathrm{L}^{-1}\right)$ & - & 13 & 258,3 & 170,8 \\
Cloreto $\left(\mathrm{mg} \mathrm{de} \mathrm{L}^{-1}\right)$ & 11,01 & 753,6 & 326,6 & 527,5 \\
Sódio $\left(\mathrm{mg} \mathrm{L}^{-1}\right)$ & 2,53 & 568,5 & 585,3 & 580,0 \\
Potássio $\left(\mathrm{mg} \mathrm{L}^{-1}\right)$ & 1,17 & 31,2 & 23,8 & 25,4 \\
Sulfato $\left(\mathrm{mg} \mathrm{L}^{-1}\right)$ & 4,67 & 43,2 & 110,6 & 54,8 \\
Nitrogênio total Kjedhal $\left(\mathrm{mg} \mathrm{L}^{-1}\right)$ & - & 11,3 & 6,9 & - \\
Nitrogênio amoniacal $\left(\mathrm{mg} \mathrm{L}^{-1}\right)$ & - & 2,81 & - & - \\
Cálcio $\left(\mathrm{mg} \mathrm{L}^{-1}\right)$ & 0,8 & 1456 & 80,6 & 370,2 \\
Magnésio $\left(\mathrm{mg} \mathrm{L}^{-1}\right)$ & 1,94 & 78,6 & 28,9 & 61,4 \\
\hline - não detectado & \multicolumn{4}{c}{}
\end{tabular}


das mudanças ocorridas nos processos de produção industrial no decorrer do tempo permitindo assim, adicionar fertilizantes em quantidades suficientes para obtenção das soluções nutritivas preconizadas por Moraes \& Furlani (1999), considerando a primeira fase até 37 dias, a segunda de 38 a 77 dias e a terceira de 77 a 127 dias após transplante da cultura.

$\mathrm{O}$ delineamento experimental utilizado foi inteiramente casualizado, com seis tratamentos constituídos por T1 $=100 \%$ AA (solução comercial - SC); T2 $=75 \%$ AA $+25 \%$ EI com complementação de nutrientes; $\mathrm{T} 3=50 \% \mathrm{AA}+50 \%$ de EI com complementação de nutrientes; T4 $=25 \%$ AA $+75 \%$ EI com complementação de nutrientes; T5 $=100 \%$ EI com complementação de nutrientes e T6 $=100 \%$ EI sem complementação de nutrientes, cada um com quatro repetições. A composição química do T1 (SC), tal como os tratamentos que receberam efluentes complementados com nutrientes, foi calculada com base na formulação proposta por Moraes \& Furlani (1999), descrita na Tabela 2.

Tabela 2. Composição da recomendação quantitativa dos nutrientes para as distintas fases do ciclo da cultura do tomate (concentração em $\mathrm{mg} \mathrm{L}^{-1}$ )

\begin{tabular}{crrrll}
\hline \multicolumn{7}{c}{ Fases da cultura } \\
\hline Macronutrientes & \multicolumn{1}{c}{ A } & \multicolumn{1}{c}{ B } & \multicolumn{1}{c}{ C } & \multicolumn{2}{c}{ Micronutrientes } \\
$\mathrm{NO}_{3}$ & 135 & 150 & 164 & $\mathrm{~B}$ & 0,50 \\
$\mathrm{NH}_{4}$ & 35 & 37 & 38 & $\mathrm{Cu}$ & 0,05 \\
$\mathrm{P}$ & 52 & 52 & 42 & $\mathrm{Fe}$ & 2,40 \\
$\mathrm{~K}$ & 341 & 326 & 409 & $\mathrm{Mn}$ & 0,75 \\
$\mathrm{Ca}$ & 152 & 190 & 209 & $\mathrm{Mo}$ & 0,06 \\
$\mathrm{Mg}$ & 40 & 40 & 40 & $\mathrm{Zn}$ & 0,11 \\
$\mathrm{~S}$ & 70 & 70 & 70 & & \\
\hline
\end{tabular}

As mudas de tomate (grupo cereja, cv. Dellycia) foram produzidas em bandejas de poliestireno expandido em 128 células preenchidas com substrato de pó de coco. Após o período de germinação as plântulas foram transferidas para a casa de vegetação para o período de aclimatação e irrigadas com solução nutritiva a $50 \%$ da concentração indicada na Tabela 2.

Quando as plantas apresentaram cinco folhas definitivas foram transplantadas para as unidades experimentais (perfis). As plantas foram tutoradas em espaldeiras verticais de $2,5 \mathrm{~m}$ de altura, com o auxílio de fitilho, e em seguida conduzidas em haste única. Os frutos eram colhidos duas vezes por semana, quando do início da mudança de coloração, de verde para vermelho. Houve eliminação de brotos laterais e foram aplicados produtos fitossanitários recomendados para o controle de pragas e doenças (Arruda Júnior et al., 2011).

As soluções nutritivas foram fornecidas de forma automática, com o auxílio de temporizador, por meio de uma vazão de $4 \mathrm{~L} \mathrm{~min}^{-1}$. Cada vez em que o sistema era acionado, possibilitava 15 min com irrigaçãoe 15 min sem irrigação, das 6 às $18 \mathrm{~h}$. No período das 18 às $6 \mathrm{~h}$, o sistema foi programado para promover um evento de irrigação a cada hora, conforme recomendado por Pilau et al. (2002).

O quantitativo de macro e micronutrientes a ser adicionado em cada tratamento foi determinado de acordo com os nutrientes existentes no efluente, o nível de diluição dos tratamentos e as fases de desenvolvimento da cultura (Fases A, B e C) (Tabela
2). O T6 (100\% efluente) não foi complementado com nutrientes em nenhuma fase do cultivo, sendo utilizados apenas os nutrientes que existiam no efluente de sorvete (Tabela 1).

As soluções nutritivas foram monitoradas diariamente registrando-se e corrigindo, quando necessário, o volume de água, o pHe a condutividade elétrica (CE) (Martinez, 1999). O valor de $\mathrm{pH}$ se manteve entre 5,5 a 6,5, durante a execução do experimento. A CE era quantificada para diagnosticar a concentração de sais totais na solução nutritiva, tendo como limites mínimos, $1 \mathrm{dS} \mathrm{m}^{-1}$ na fase A e $1,5 \mathrm{dS} \mathrm{m}^{-1}$ nas fases B e C (Moraes \& Furlani, 1999). Quando a CE atingia valores abaixo de $1 \mathrm{dS} \mathrm{m}{ }^{-1}$, ocorria a troca da solução nutritiva completa. No respectivo experimento foram realizadas duas trocas de solução, sendo a primeira troca (30 dias após o transplantio - DAT) compreendendo o início da fase $\mathrm{B}$ e a segunda troca se deu no início da fase C (60 DAT).

A medição do consumo hídrico da cultura se iniciou a partir da reposição diária do nível do reservatório $(40$ L) da solução nutritiva, com o auxílio de uma proveta graduada, utilizando-se água do abastecimento.

Para avaliação das medidas biométricas foram analisadas as variáveis massa fresca da parte aérea (MFPA), massa fresca do fruto (MFF) e número de frutos (NF). As demais variáveis analisadas foram determinadas após secagem em estufa a $65^{\circ} \mathrm{C}$ até atingir massa constante, como massa seca da parte aérea (MSPA), massa seca do fruto (MFS) e massa seca da raiz (MSR).

A eficiência do uso da água (E.U.A) foi determinada pela relação entre produtividade e volume total de água consumida pela cultura. A eficiência do uso da água $\left(\mathrm{g} \mathrm{L}^{-1}\right)$ foi calculada em função das diferentes concentrações de efluentes, considerando-se: a produtividade de frutos (MFF) e o consumo de água (L); a produtividade de massa seca da parte aérea (MSPA) e o consumo de água (L) de acordo com a metodologia descrita por Fagan et al. (2009).

As variáveis foram avaliadas pelo teste $\mathrm{F}$ utilizando-se o programa estatístico SAS e as que obtiveram efeitos significativos foram submetidas à análise de regressão, visando ajustar modelos de comportamento. Também foram realizados contrastes entre a solução nutritiva comercial e cada tratamento composto por efluente, mediante comparação de médias a nível de 0,05 de probabilidade.

\section{RESULTADOS E DISCUSSÃO}

\section{Efeito sobre o consumo hídrico}

A salinidade nas soluções nutritivas hidropônicas, expressa em condutividade elétrica (Figura 1), acarreta menor consumo hídrico por parte da planta devido à retenção osmótica da água, a existência de íons em altas concentrações, principalmente sódio e cloreto, e a interação entre íons resulta em uma disponibilidade menor de água para as plantas.

O consumo hídrico observado ao longo dos 126 dias após o transplantio apresentou comportamento linear decrescente com o aumento da condutividade elétrica, nos respectivos tratamentos: consumo hídrico médio para o T1 (solução comercial - SC) foi de 120,8 L planta ${ }^{-1}$, para T2 106,4 L planta $^{-1}$ para T3 90,46 L planta $^{-1}$, para T4 68,6 L planta ${ }^{-1}$ e para T5 49,5 L 


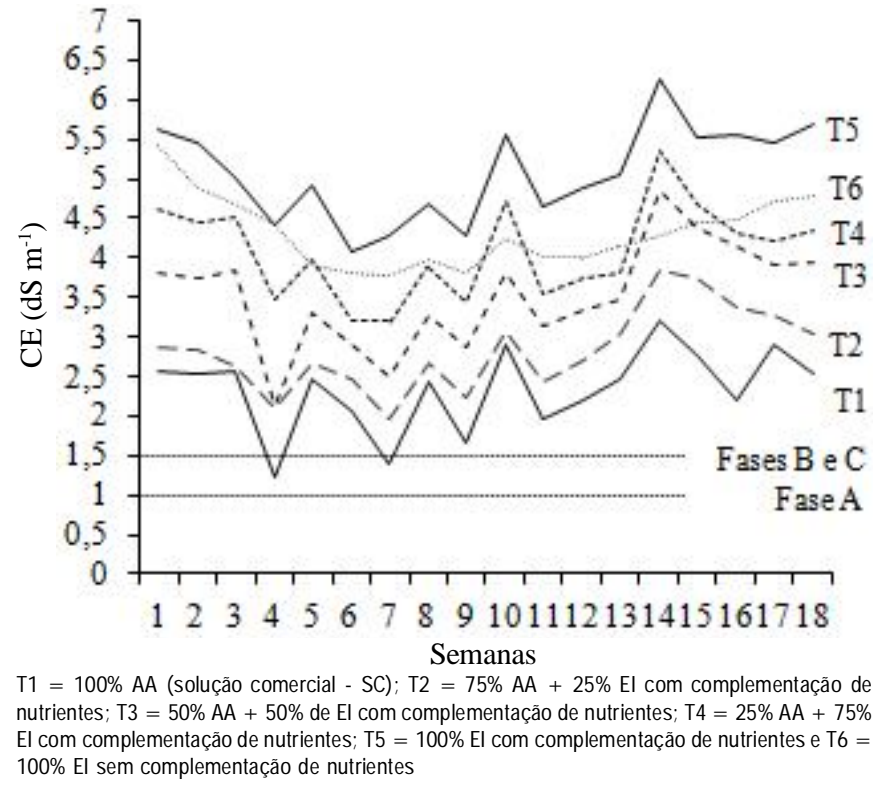

Figura 1. Condutividade elétrica das soluções nutritivas em função das diferentes concentrações de efluentes

planta $^{-1}$. Comparando, percentualmente, o T1 com as soluções de efluente acrescido de nutrientes, reduções foram observadas no consumo hídrico em $11,92 \%$ ao se utilizar $25,14,98 \%$ com $50,43,21 \%$ com 75 e $59,02 \%$ com $100 \%$ de efluente complementado com nutrientes, respectivamente (Figura 2). $\mathrm{O}$ consumo médio do tratamento com $100 \%$ de efluente sem complementação de nutrientes (T6) foi de $15 \mathrm{~L} \mathrm{planta}^{-1}$.

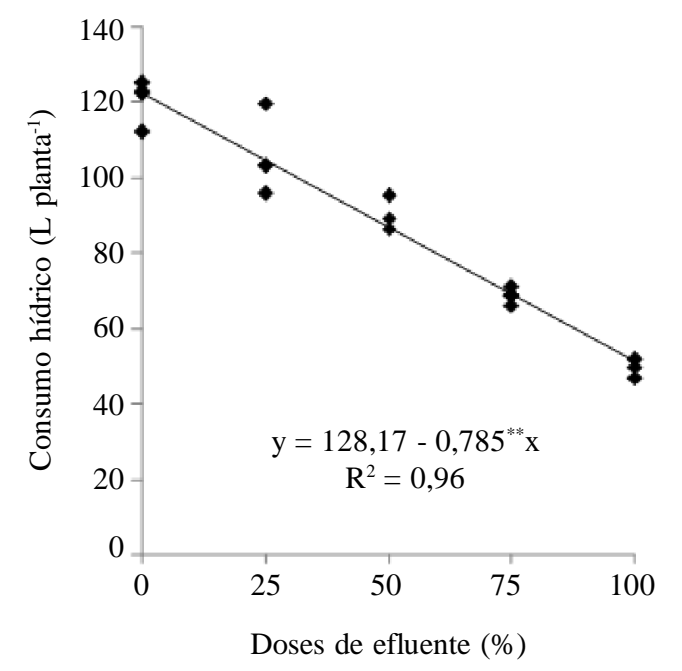

Figura 2. Consumo hídrico do tomate cereja hidropônico em função das diferentes doses de efluente

Gomes et al. (2011) observaram efeito linear decrescente no consumo hídrico de tomate cereja hidropônico, com o aumento da condutividade elétrica na solução nutritiva e obtiveram reduções no consumo hídrico da testemunha com o uso de doses crescentes $(25 ; 50 ; 75$ e $100 \%)$ de rejeito salino em 4,59; 15,$82 ; 23,58$ e $28,72 \%$, respectivamente.

Apresenta-se, na Figura 3, o monitoramento climático no interior da casa de vegetação para o período do experimento. Observou-se uma temperatura média, máxima e mínina de 27,0, 34,0 e $23,5^{\circ} \mathrm{C}$, respectivamente; esta variação de temperatura
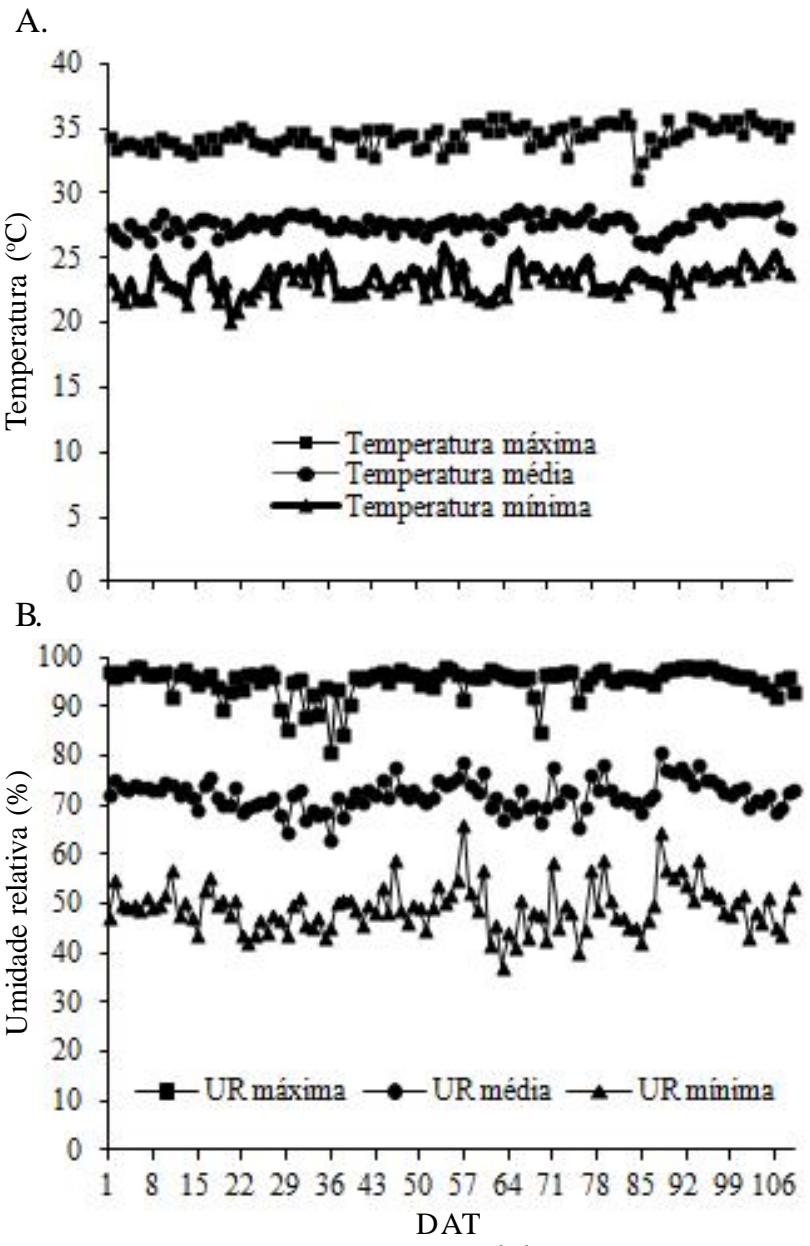

Figura 3. Variação da temperatura (A) e umidade relativa do ar (B) no interior da casa de vegetação

encontra-se dentro da faixa de tolerância da cultura que é de 10 a $35^{\circ} \mathrm{C}$ (Alvarenga, 2004). Para a umidade relativa do ar, observouse média, máxima e mínima de 71, 95 e 49\%, respectivamente.

\section{Efeitos sobre os parâmetros agronômicos}

O estresse devido à concentração dos íons no efluente ocasionou efeito significativo com tendência quadrática no peso das plantas, em termos de acúmulo na massa fresca (MFPA) e seca da parte aérea (MSPA) (Figura 4A e B).

A utilização de efluente a 100\% (T6), acarretou plantas com nanismo e inibição do crescimento da raiz. Esta inibição no crescimento das plantas se deve ao não desenvolvimento e ao alongamento das células, à existência de ramos atrofiados e menor área foliar, resultando em plantas com menor massa seca na raiz, 17,7 g planta $^{-1}$, e, consequentemente, menor massa seca na parte aérea $2,42 \mathrm{~g}_{\text {planta }}{ }^{-1}$. Além do efeito salino, resultando em CE média de 4,32 dS m${ }^{-1}$, a diminuição de nutrientes essenciais acarreta incapacidade da planta em desenvolver e, contrapartida, completar seu ciclo de vida (Larcher, 2004).

A adição de efluente proporcionou redução crescente na MFPA, efeito observado quando foi comparado à SC com os demais tratamentos que receberam efluente complementado com nutrientes obtendo-se, então, reduções de 9,86, 33,81, 62,89 e $66,63 \%$ para as doses com 25, 50, 75 e $100 \%$ de efluente complementado com nutrientes, respectivamente. Previa-se que o tratamento com SC apresentasse maior desenvolvimento na 
A.

B.
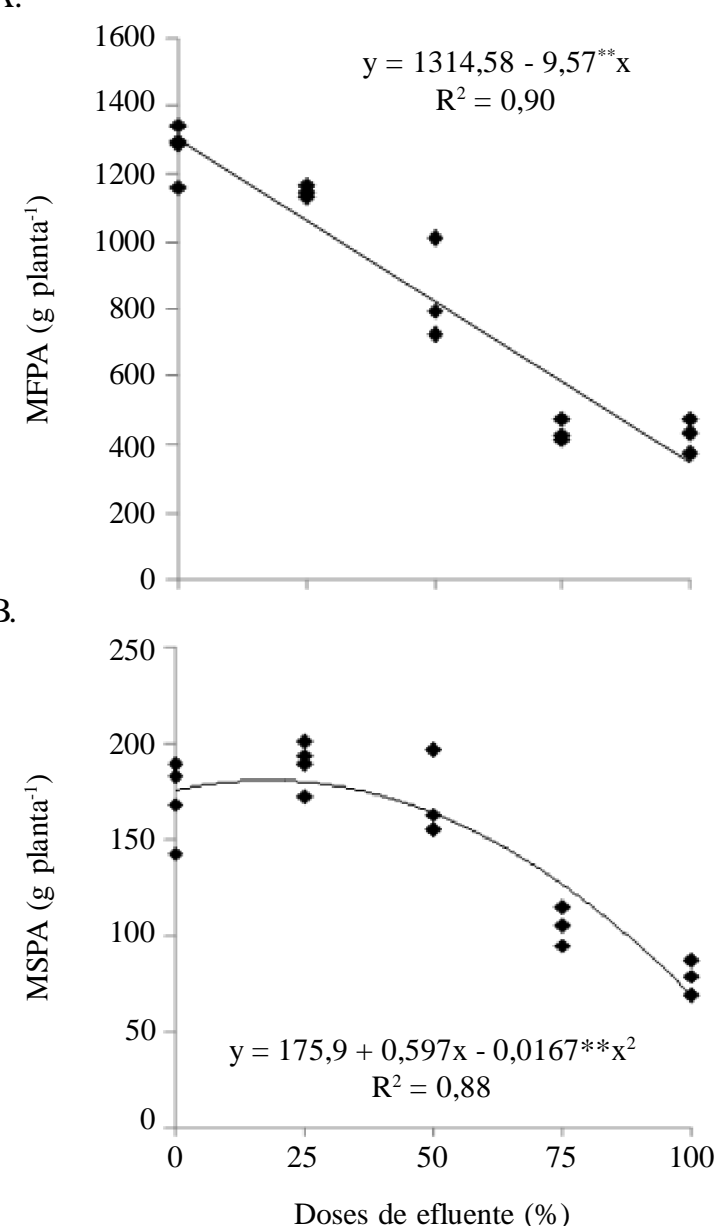

Figura 4. Matéria fresca - MFPA (A) e massa seca M SPA (B) da parte aérea do tomate cereja em função de diferentes concentrações de efluente

parte aérea em virtude da menor competição de íons, sobremaneira de cálcio e sódio existentes em grande quantidade no efluente de sorvete, o que pode resultar em efeitos antagônicos e inibitórios na absorção de íons e, em consequência, redução no crescimento das plantas. A massa fresca média da parte aérea e do T6, foi de 10,36 g planta $^{-1}$.

Na variável MSPA a dose com $25 \%$ (T2) obteve ganho de $10 \%$ quando comparada com a SC, devido à semelhança das composições químicas de ambas as soluções nutritivas e ao menor efeito do estresse salino para esta diluição, quando comparado com os outros tratamentos que receberam efluentes. A redução linear decrescente no peso das plantas em função do aumento salino das soluções nutritivas, está de acordo com os resultados obtidos por Cosme et al. (2011), Gomes et al. (2011) e Oliveira et al. (2007), ao verificaram a ocorrência de redução significativa da MFPA e, consequentemente, na MSPA em plantas de tomate.

$\mathrm{O}$ aumento das doses de efluente contribuiu para um crescimento menor das raízes. A dose de 50\% (T3) apresentou melhor valor no ganho de massa dentre as soluções que continham efluente quando comparada com a SC, resultando em tendência linear decrescente com o coeficiente angular de 0,78 , significativo a 0,01 e o linear de 228,37 , significativo a 0,05 , com o aumento das doses, entretanto, apresentando um coeficiente de determinação de 0,46 . Para a parcela que continha somente solução comercial (SC), em média matéria seca da raiz do tomate cereja foi de $235,0 \mathrm{~g} \mathrm{planta}^{-1}$.

O aumento da salinidade na água de irrigação ocasionou inibição gradativa no crescimento radicular das plantas de tomate cereja, resultado semelhante ao obtido por Medeiros et al. (2011).

Para as variáveis MFF (Figura 5A), MSF (Figura 5B) e número de frutos (NF) (Figura 5C), a dose com $25 \%$ de efluente (T2)

A.

B.
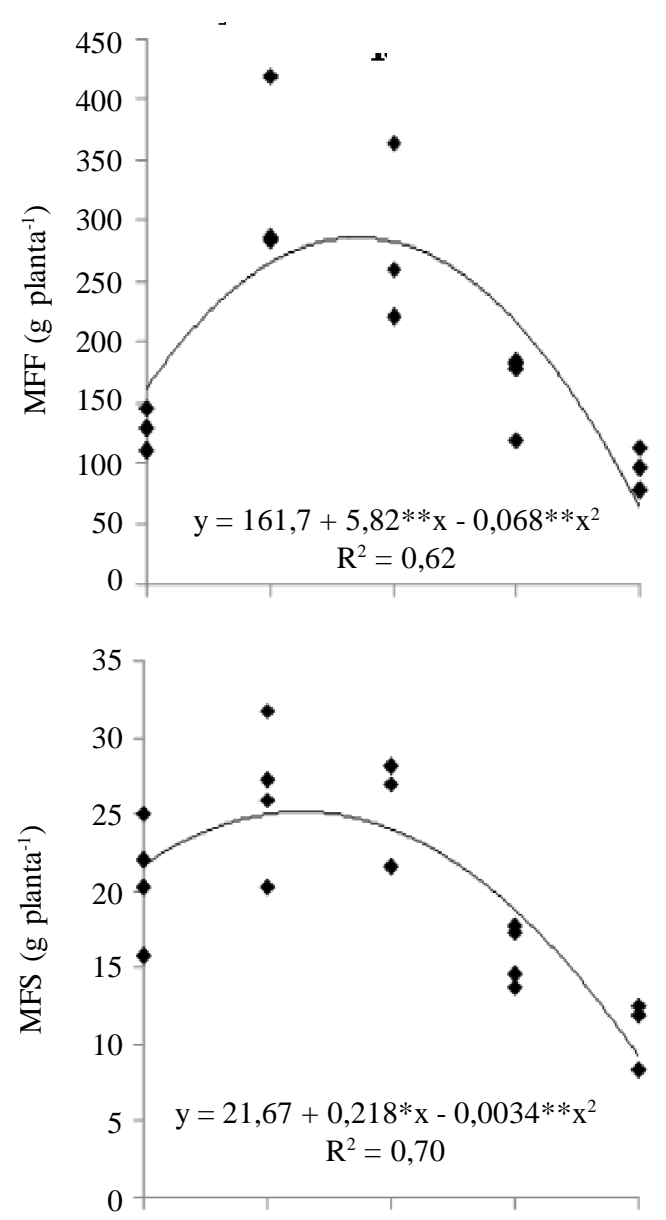

C.

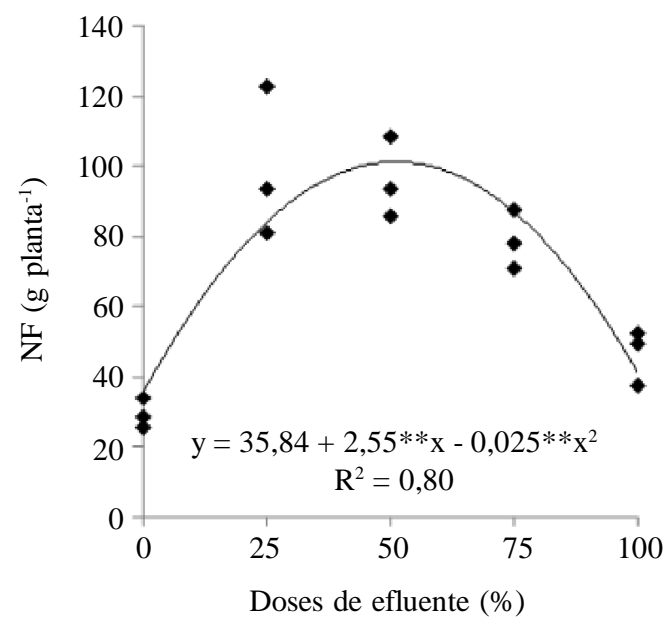

Figura 5. Massa fresca dos frutos - MFF (A), massa do fruto seco - MFS (B) e número de frutos - NF (C) em função de diferentes concentrações de efluente adicionados a solução nutritiva 
promoveu melhor produtividade quando comparada com a SC, obtendo aumentos de 61,$27 ; 24,01$ e 70,71\%, respectivamente. Em termos de produtividade, os resultados obtidos foram semelhantes ao recomendado por Gomes et al. (2011), ao adicionarem $25 \%$ de rejeito salino na solução nutritiva sem haver perda de produção no cultivo de tomate cereja hidropônico enquanto Al-Lahham et al. (2003) obtiveram melhor produtividade utilizando $100 \%$ de água residuária oriunda de esgoto doméstico da cidade de Amman/Jordânia, na irrigação com tomate.

Segundo Souza et al. (2010), a utilização de efluente oriundo de suinocultura com pretratamento físico possibilita, na irrigação, melhor crescimento das plantas de tomate quando comparado com adubação convencional, devido à existência de nutrientes essenciais para o desenvolvimento das plantas porém, segundo Sousa et al. (2005), tal uso pode ser danoso à produção quanto à existência de salinidade, sodicidade e excesso de nutrientes. No presente trabalho verificou-se que a adição de efluente com 25, 50 e 75\%, nas composições volumétricas das soluções nutritivas, possibilitou aumento na produção de frutos em 61,27, 45,28 e 23,02\%, respectivamente, em relação à SC, o que corrobora com Soares et al. (2007) ao relatarem maior tolerância das plantas à salinidade quando cultivadas em sistemas hidropônicos, em virtude da inexistência do potencial mátrico, possibilitando aumento do potencial total da água e uma absorção melhor de água, pelas plantas.

A utilização de doses crescentes de efluentes resultou em condutividades elétricas crescentes ao longo do experimento tendo-se obtido, em média, com o uso de $25 \%$, o valor de 3,01 $\mathrm{dS} \mathrm{m}^{-1}$ com $50 \%$ o valor de $4,16 \mathrm{dS} \mathrm{m}^{-1} ;$ com $75 \%$ o valor de 4,89 $\mathrm{dS} \mathrm{m} \mathrm{m}^{-1}$ e com $100 \%$ (T5) o valor de $5,82 \mathrm{dS} \mathrm{m}^{-1}$ (Figura 1).

Segundo Cosme et al. (2011) o aumento progressivo da CE na água utilizada para irrigação ocasiona perda na produção de frutos. No experimento foram obtidos ganhos na produtividade para todas as doses que receberam efluentes mais complementação de nutrientes, com exceção do T6 (sem a adição de nutrientes) resultando em perda de $26 \%$ na MSF quando comparada com a SC.

Ao longo do ciclo da cultura plantas de tomate com deficiência nutricional ocasionam queda de flores e frutos, devido à morte da gema apical (Silva et al., 2006). Logo, NF quantificado na SC foi inferior quando comparado aos demais tratamentos, com exceção do tratamento que recebeu apenas efluente compro- vando, assim, a viabilidade do uso do efluente tratado de indústria de sorvete como fonte de cálcio (Figura 5C).

Além da CE, as características climáticas, a composição química da água e a cultivar utilizada em cultivos de tomate, resultam em diferentes respostas à salinidade, podendo o tomate passar de moderadamente sensível a moderadamente tolerante quando irrigado com água salina (Eloi et al., 2011).

A dose (composta por efluente com complementação de nutrientes) ótima foi estimada em 42,79\% para a MFF, o que resultaria em uma produção máxima de $286,42 \mathrm{~g} \mathrm{planta}^{-1} \mathrm{e}$ para o NF, a dose ótima foi de $51 \%$ resultando em 100,86 frutos por planta.

Em geral, o consumo hídrico e as variáveis biométricas decresceram com o aumento das doses de efluente, ocorrendo diferenças significativas em todas as varáveis analisadas (Tabela 3) fato também observado por Cosme et al. (2011) e Oliveira et al. (2007) ao avaliarem o efeito de diferentes níveis de salinidade para MSPA, MFPA e MFF. A CE da água de irrigação utilizada pelos autores citados anteriormente, foi superior quando comprada com a CE utilizada o que evidencia, sem dúvida, maior estresse salino sofrido pela cultura.

Avaliando os tratamentos que receberam doses de efluentes comparados com a SC, o uso com $25 \%$ de efluente complementada com nutrientes proporcionou maior consumo hídrico, ganho em massa na parte aérea e maior produtividade (Tabela 3).

A produtividade, expressa pela MFF e MFS, obtida nas doses de 25 e $50 \%$ de efluente, foi superior à SC; portanto, o uso de efluente da indústria de sorvete pode ser uma alternativa de uso e substituição parcial dos nutrientes existentes na SC. $\mathrm{O}$ uso de concentrações de efluente acima de $50 \%$ pode acarretar em perdas na produtividade do tomate cereja sob condições hidropônicas do tipo NFT. Os efeitos deletérios provocados pela adição de sais nas soluções nutritivas ocasionaram redução em $51 \%$ na produtividade do tomateiro, conforme observado por Cosme et al. (2011).

\section{Análise da eficiência do uso da água}

Ocorreu diferença significativa para a eficiência do uso da água (E.U.A) na produção de matéria seca da parte aérea (Figura 6A) e na produtividade (Figura 6B), com comportamento quadrático, em função do aumento das doses de efluente na solução nutritiva.

Tabela 3. Contraste entre a solução comercial (SC) e os tratamentos com doses de efluentes sobre o consumo hídrico, massa fresca da parte aérea (M FPA), massa seca da parte aérea (M SPA), massa seca da raíz (M SR), massa fresca do fruto (MFF), massa seca do fruto (MFS) e número de frutos (N F)

\begin{tabular}{|c|c|c|c|c|c|c|c|}
\hline \multirow{2}{*}{ Tratamentos } & \multirow{2}{*}{$\begin{array}{l}\text { Consumo hídrico } \\
\left(\text { L planta }^{-1}\right)\end{array}$} & MFPA & MSPA & MSR & MFF & MFS & \multirow{2}{*}{ NF } \\
\hline & & \multicolumn{5}{|c|}{ (g planta ${ }^{-1}$ ) } & \\
\hline $\mathrm{T} 1$ & 120,80 & 1270,89 & 170,57 & 238,63 & 128,83 & 20,80 & 29,20 \\
\hline $\mathrm{T} 2$ & $106,40 * *$ & $1145,57 * *$ & $189,13^{\text {ns }}$ & $185,63 * *$ & $330,54 * *$ & $26,33 * *$ & $99,03 * *$ \\
\hline T3 & $90,46 * *$ & $841,10 * *$ & $171,53^{\mathrm{ns}}$ & $221,32^{\mathrm{ns}}$ & $282,70 * *$ & $25,59^{\text {ns }}$ & $95,80 * *$ \\
\hline $\mathrm{T} 4$ & $68,60 * *$ & $471,56 * *$ & $104,82^{* *}$ & $163,97^{* *}$ & $166,30^{\text {ns }}$ & $15,87^{*}$ & $78,66 * *$ \\
\hline T5 & $49,50 * *$ & $424,10 * *$ & $78,04^{* *}$ & $144,34 * *$ & $95,91^{\mathrm{ns}}$ & $10,94 * *$ & $46,20^{\text {ns }}$ \\
\hline T6 & $15,00 * *$ & $10,36 * *$ & $2,42^{* *}$ & $17,77^{* *}$ & $1,19 *$ & $0,47 * *$ & $0,40 *$ \\
\hline CV $(\%)$ & 7,62 & 10,43 & 11,9 & 10,61 & 27,05 & 18,92 & 18,90 \\
\hline
\end{tabular}

ns - não significância em relação ao T1; * diferença significativa em relação a T1 a nível de 0,05 de probabilidade; ** diferença significativa em relação a T1 a nível de 0,01 de probabilidade

$\mathrm{T} 1=100 \%$ AA (solução comercial $-\mathrm{SC}$ ) $; \mathrm{T} 2=75 \% \mathrm{AA}+25 \% \mathrm{El}$ com complementação de nutrientes; $\mathrm{T} 3=50 \% \mathrm{AA}+50 \%$ de El com complementação de nutrientes; T4 = $25 \% \mathrm{AA}+75 \%$ El com complementação de nutrientes; T5 $=100 \%$ El com complementação de nutrientes e T6 $=100 \% \mathrm{El}$ sem complementação de nutrientes 
A.

B.

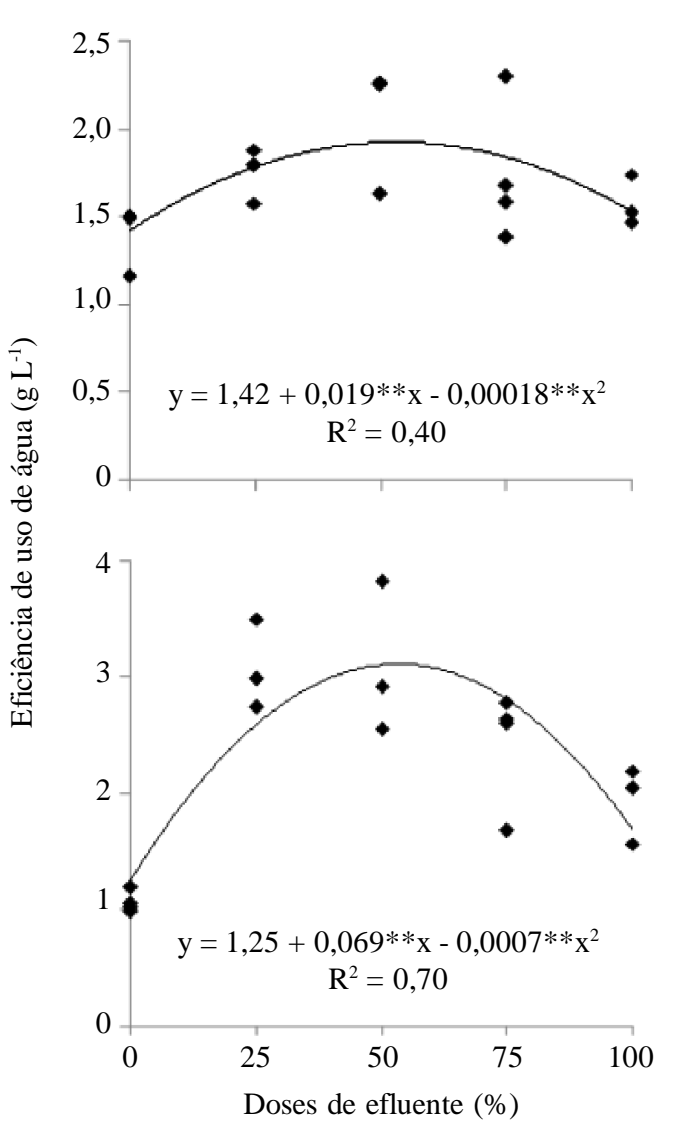

Figura 6. Eficiência de uso de água na produtividade de massa seca parte aérea (A) e produtividade (B) em função de diferentes concentrações de efluente adicionados à solução nutritiva

A produção de massa seca na parte aérea por unidade de água aplicada resultou em valores de E.U.A de 1,$41 ; 1,75 ; 2,05$; 1,73 e $1,57 \mathrm{~g} \mathrm{~L}^{-1}$ ao se utilizar os tratamentos $\mathrm{T} 1$; T2; T3; T4 e T5, respectivamente. Ao comparar os tratamentos que receberam a adição de efluentes tratados, observa-se ganho na massa seca, de 0,$37 ; 0,49 ; 0,13$ e $0,16 \mathrm{~g}$ por litro de água consumido, utilizando-se doses de efluente com 25; 50; 75 e $100 \%$ de efluente complementado com nutrientes, respectivamente (Figura 6A). O uso de efluente de sorvete a 100\% sem complementação de nutrientes (T6) produziu, para cada unidade de água consumida durante o cultivo, $0,16 \mathrm{~g}$ de MSPA.

O comportamento dos valores obtidos para a eficiência do uso da água (E.U.A) sobre a produtividade variou significativamente em função da diluição de efluente na solução nutritiva tendo-se obtido, com as doses 0; 25; 50; 75 e 100\% de efluente complementado com nutrientes, eficiências de 1,05; 3,$08 ; 3,10 ; 2,43 \mathrm{e} 1,94 \mathrm{~g} \mathrm{~L}^{-1}$, respectivamente. A diferença entre as doses de efluente com a SC possibilitou ganho de 2,03; 2,05; 1,38 e 0,89 $\mathrm{g} \mathrm{L}^{-1}$ para o T2; T3; T4 e T5 (Figura 6B) e o uso do T6 resultou em $0,09 \mathrm{~g} \mathrm{~L}^{-1}$ de eficiência do uso da água.

O comportamento dos valores de E.U.A pode variar em função de grupos ou cultivares de tomate, tipo de irrigação, condições climáticas e qualidade da água. Abrahão (2011) verificou diferentes eficiências de uso da água nas cultivares de tomate cereja Swett Milion $\left(29,1 \mathrm{~kg} \mathrm{~m}^{-3}\right)$ e com a Sweet Grape $\left(22,3 \mathrm{~kg} \mathrm{~m}^{-3}\right)$. Neste trabalho o maior valor da E.U.A obtido foi com a adição de $50 \%$ de efluente na composição da solução nutritiva em razão principalmente de um consumo hídrico menor agregado a este tratamento mantendo-se a produtividade superior ao tratamento com solução comercial e igual estatisticamente ao tratamento com $25 \%$ de efluente resultando em um ganho de $31 \mathrm{~kg} \mathrm{~m}^{-3}$.

\section{CONCLUSÕES}

1. O aumento das doses de efluente tratado promoveu redução linear no consumo hídrico das plantas;

2. O uso de $25 \%$ de efluente tratado na solução nutritiva proporcionou a maior produtividade de frutos por planta;

3. A adição de $50 \%$ de efluente tratado na solução nutritiva possibilitou maior substituição parcial dos adubos químicos sem comprometer a produtividade, como também obteve a maior eficiência do uso da água, tanto para fruto como para matéria seca da parte aérea;

4. A utilização das doses com 75 e $100 \%$ de efluente tratado acrescido com nutrientes e $100 \%$ de efluente sem nutrientes provocou maiores efeitos no aumento da salinidade, reduzindo progressivamente a produção de massa na parte aérea e a produtividade do tomate cereja.

\section{AgRADECIMENTOS}

Os autores agradecem ao Programa de Pós-graduação em Engenharia Agrícola da UFRPE; à Coordenação de Aperfeiçoamento de Pessoal de Nível Superior (CAPES/PNPD); à Fundação de Amparo à Ciência e Tecnologia do Estado de Pernambuco (FACEPE); ao Conselho Nacional de Desenvolvimento Científico e Tecnológico (CNPQ) pela concessão das bolsas e ao Instituto Nacional de Ciência e Tecnologia em Salinidade (INCTSal).

\section{LITERATURA CITADA}

Abrahão, C. Relação K:Ca:Mg na solução nutritiva para o cultivo de mini tomate em substrato. Botucatu: FCA/UNESP. 2011. 86p. Dissertação Mestrado

Agrianual. Anuário da agricultura brasileira. São Paulo: Instituto FNP, 2009. 497p.

Al-Lahham, O.; El Assi, N. M.; Fayyad, M. Impacto of treated wastewater irrigation on quality attributes and contamination of tomato fruit. Agricultural Water Management, v.61, p.5162, 2003.

Alvarenga, M. A. R. Tomate: produção em campo, casa-devegetação e em hidroponia. Lavras: UFLA. 2004. 400p.

Arruda Júnior, S. J.; Bezerra Neto, E.; Barreto, L. P.; Resende, L. V. Podridão apical e produtividade do tomateiro em função dos teores de cálcio e amônio. Revista Caatinga, v.24, p.2026, 2011.

Bastos, R. K. X.; Mara, D. D. The bacterial quality of salad crop drip and furrow irrigated with waste stabilization pond effluent: An evaluation of the WHO guidelines. Water Science and Technology, v.31, p.425-430, 1995. 
Cosme, C. R.; Dias, N. da S.; Oliveira, A. M.; Oliveira, E. M. M.; Sousa Neto, O. N. Produção de tomate hidropônico utilizando rejeito da dessalinização na solução nutritiva aplicados em diferentes épocas. Revista Brasileira de Engenharia Agrícola e Ambiental, v.15, p.499-504, 2011.

Eloi, W. M.; Duarte, S. N.; Soares, T. M.; Silva, E. F. F.; Miranda, J. H. Rendimento comercial do tomateiro em resposta à salinização ocasionada pela fertirrigação em ambiente protegido. Revista Brasileira de Engenharia Agrícola e Ambiental, v.15, p.471-476, 2011.

Fagan, E. B.; Petter, S. L.; Simon, J.; Borcioni, E.; Luz, J. L.; Manfron, P. A. Eficiência do uso de água do meloeiro hidropônico. Bioscience Journal, v. 25, p.37-45, 2009.

Filgueira, F. A. R. Novo Manual de Olericultura: agrotecnologia moderna na produção e comercialização de hortaliças. 3.ed.Viçosa: UFV, 2008. 421p.

Freire, A. L. O.; Saraiva, V. P.; Miranda, J. R. P.; Bruno, G. B. Crescimento, acúmulo de íons e produção de tomateiro irrigado com água salina. Semina: Ciências Agrárias, v.31, p.1113-1114, 2010.

Gomes, J. W. S.; Dias, N. da S.; Oliveira, A. M.; Blanco, F. F.; Sousa Neto, O. N. Crescimento e produção de tomate cereja em sistema hidropônico com rejeito de dessalinização. Revista Ciência Agronômica, v.42, p.850-856, 2011.

Larcher, W. Ecofisiologia vegetal. São Carlos: RIMA, 2004. 531p.

Loos, R. A.; Silva, D. J. H.; Fontes, P. C. R.; Picanço, M. C. Identificação e quantificação dos componentes de perdas de produção em ambiente protegido. Horticultura Brasileira, v.26, p.281-286, 2008.

Martinez, H. E. P. Hidroponia. In: Recomendações para uso de corretivos e fertilizantes em Minas Gerais. Ribeiro, A. C.; Guimarães, P.T. G;Alvarez, V.H. Viçosa: SBCS, 5.ed., 1999.359p.

Medeiros, R. F.; Cavalcante, L. F.; Mesquita, F. O.; Rodrigues, R. M.; Sousa, G. G.; Diniz, A. A. Crescimento inicial do tomateiro-cereja sob irrigação com águas salinas em solo com biofertilizantes bovino. Revista Brasileira de Engenharia Agrícola eAmbiental, v.15, p.505-511, 2011.

Moraes, C. A. G.; Furlani, P. R. Cultivo de hortaliças de frutos em hidroponia em ambiente protegido. In: Cultivo protegido de hortaliças em solo e hidroponia. Informe Agropecuário, v.21,p.105-113, 1999.
Navarro, J. M.; Garrido, C.; Martinez, V.; Carvajal, M. Water relations and xylem transport of nutrients in pepper plants grown under two different salts stress regimes. Plant Growth Regulation, v.41, p.237-245, 2003.

Oliveira, B. C.; Cardoso, M. A. A.; Oliveira, J. C.; Oliveira, F. A. de; Cavalcante, L. F. Características produtivas do tomateiro submetido a diferentes níveis de sais, na água de irrigação. Revista Brasileira de Engenharia Agrícola e Ambiental, v.11, p.11-16, 2007.

Paganini, W. S. Reuso de água na agricultura. In: Mancuso, P. C. S.; Santos, H. F. Reuso de água. Barueri: Manole, p.339401, 2003.

Pilau, F. G.; Medeiros, S. L. P.; Manfron, P. A.; Bianchi, S. A. Influência do intervalo entre irrigações na produção e nas variáveis fisiológicas da alface hidropônica. Revista Brasileira de Agrometeorologia, v.20, p.237-244, 2002.

Silva, J. B. C.; Giordano, L. B.; Furumoto, O.; Boiteux, L. S.; França, F. H.; Villas-Boas, G. L. V.; Branco, M. C.; Medeiros, M. A.; Marouelli, W; Lopes, C. A.; Ávila, A. C.; Nascimento, W. M.; Pereira, W. Cultivo de tomate para industrialização. Brasília: Embrapa Hortaliças, Sistemas de Produção, 2.ed. 2006. s.p.

Soares, T. M.; Silva, E. F. F.; Duarte, S. N.; Melo, R. F.; Jorge, C. A.; Bonfim-Silva, E. M. Produção de alface utilizando águas salinas em sistema hidropônico. Irriga, v.12, p.235-248, 2007.

Sousa, J. T.; van Haandel, A. C.; Cavalcanti, P. F. F.; Figueiredo, A. M. F. Tratamento de esgoto para uso na agricultura do semiárido nordestino. Engenharia Sanitária Ambiental, v.10, p.260-265, 2005.

Souza, J. A. R.; Moreira, D. A.; Ferreira, P. A. Parâmetros de crescimento de tomateiros produzidos com água residuária de suinocultura. Engenharia Ambiental, v.7, p.97-109, 2010.

Steidle Neto, A. J.; Zolnier, S. Preparo e manejo de soluções nutritivas para cultivos hidropônicos e sem substrato. Revista Plasticultura, v.13, p.16-17, 2010.

Tuna, A. L.; Kaya, C.; Ashraf, M.; Altunlu, H.; Yokas, I.; Yagmur, B. The effects of calcium sulphate on growth membrane stability and nutrient uptake of tomato plants grown under salt stress. Environmental and Experimental Botany, v.59, p.173-178, 2007. 